\title{
Glutathione S-transferase P1 (GSTP1) polymorphism in patients with chronic obstructive pulmonary disease
}

T Ishii, T Matsuse, S Teramoto, H Matsui, M Miyao, T Hosoi, H Takahashi, Y Fukuchi, Y Ouchi

\begin{abstract}
Background-Enzymes that contribute to the local detoxification in alveoli and bronchioles have an important role in the defence mechanism against tobacco smoke. It has been suggested that genetic susceptibility to smoking injury may confer a risk for the development of chronic obstructive pulmonary disease (COPD). The polymorphisms in glutathione S-transferase P1 (GSTP1), a xenobiotic metabolising enzyme, were investigated in patients with COPD.

Methods-Polymerase chain reaction (PCR) and restriction fragment length polymorphism (RFLP) were performed to genotype GSTP1 polymorphisms in exon 5 (Ile105Val) and exon 6 (Ala114Val). Blood samples were taken from 53 patients with COPD and 50 control subjects at the Tokyo University Hospital, the Juntendo University Hospital, and the Tokyo Kenbikyoin Clinic for use in the study.

Results-The proportion of GSTP1/Ile105 homozygotes was significantly higher in the patients with COPD than in the control subjects $(79 \%$ vs $52 \%)$. The odds ratio for GSTP1/Ile105 homozygotes versus all other genotypes was 3.5 (95\% CI 2.7 to 4.6$)$ for COPD. Polymorphism at residue 114 of GSTP1 was not found in either group. Conclusions-Genetic polymorphism of exon 5 of GSTP1 may be associated with COPD because the GSTP1/Ile105 genotype is predominantly found in COPD. It is suggested that the GSTP1/Ile105 genotype may be less protective against xenobiotics in tobacco smoke.

(Thorax 1999;54:693-696)
\end{abstract}

Keywords: glutathione S-transferase P1 (GSTP1); polymorphism; chronic obstructive pulmonary disease; tobacco

Chronic obstructive pulmonary disease (COPD) is characterised by irreversible airflow limitation in the lungs. ${ }^{1}$ Although COPD is now the 12th largest burden in the world, it is estimated that it will rise to be the fifth largest burden by $2020 .^{2}$

Two major hypotheses on the cause of COPD and emphysema-namely, the protease-antiprotease hypothesis and the oxidant-antioxidant hypothesis-were put forward over 30 years ago. ${ }^{34}$ It is believed that xenobiotics, which include reactive epoxides and benzo(a)pyrene, are also involved in the pathogenesis of COPD by their ability to inhibit antiproteases ${ }^{5}$ and promote cell and tissue damage in the lungs. The most important risk factor for the development of COPD is smoking. However, only $10-20 \%$ of chronic heavy smokers develop symptomatic COPD, ${ }^{67}$ which indicates that a difference in susceptibility to tobacco smoke injury must exist and may be related to genetic factors. Furthermore, a recent study suggested that familial factors other than protease inhibitors might influence the development of airflow obstruction and chronic bronchitis. $^{8}$

Glutathione S-transferases (GSTs) consist of a superfamily of dimeric phase II metabolic enzymes that catalyse the conjugation of reduced glutathione with various electrophilic compounds. GSTs may play an important part in cellular defence by detoxifying various toxic substrates in tobacco smoke. ${ }^{9}$ GSTs are separated into the following classes: alpha (GSTA), mu (GSTM), pi (GSTP), theta, sigma, and kappa. GSTM is genetically polymorphic and it has been shown that deletion of a partial locus of this gene is associated with lung cancer and emphysema. ${ }^{10}$

Polymorphisms of GSTP1 have been reported-for example, isoleucine (Ile) 105 valine (Val) in exon 5, alanine (Ala) 114 valine (Val) in exon $6 .{ }^{11}$ The activity of this enzyme is affected by substitution at position 105 which is located in the hydrophobic substrate binding site, and this has considerable effects depending on the type of chemical reaction. ${ }^{12}$ Individuals with the $105 \mathrm{Val}$ allele have a higher risk of developing lung cancer than those with the 105Ile allele. ${ }^{13}$ However, it has recently been suggested that GSTP1/Val105 has a higher catalytic efficiency than GSTP1/Ile105 with regard to the metabolism of carcinogenic aromatic epoxides. ${ }^{14}$ In addition, GSTP1 is expressed more abundantly in alveoli, alveolar macrophages, and respiratory bronchioles than GSTM and other kinds of GSTs that are not expressed in the peripheral lungs. ${ }^{15}$

In this study we investigated whether the polymorphism of GSTP1 gene has an association with the development of COPD using a polymerase chain reaction (PCR) based genotyping assay to detect variant forms of GSTP1.

\section{Methods}

The patient group consisted of 53 men with COPD diagnosed by pulmonary function tests $\left(\mathrm{FEV}_{1} / \mathrm{FVC}<70 \%\right)$ and chest radiography who presented at the Tokyo University Hospital and the Juntendo University Hospital. Their serum 


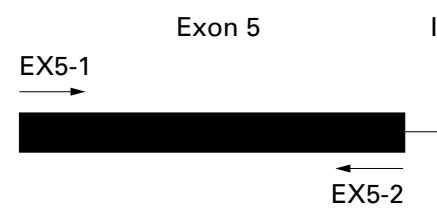

Intron 5

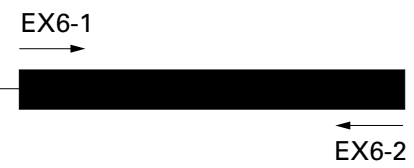

PCR and digest with Alw26I

Homozygous Heterozygote Homozygous wild type mutant mutant

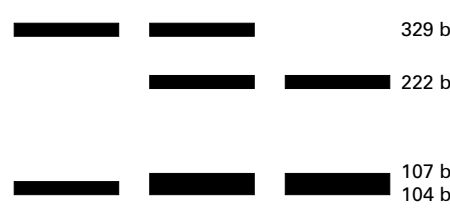

Figure 1 PCR based genotyping assays for GSTP1 polymorphism. Top panels show arrangement of exons 5 and 6. Lower panels show fragment patterns expected in individuals homozygous or heterozygous for GSTP1 polymorphisms.

$\alpha_{1}$-antitrypsin levels were within the normal range (mean (SE) $254.0 \quad(7.4) \mathrm{mg} / \mathrm{dl}$ (range 159-391)). Blood samples from 50 control healthy subjects were obtained from the Health Check Division at the Tokyo Kenbikyoin Clinic.

All the patients were diagnosed as having COPD according to the guideline of the European Respiratory Society and the definition of COPD given by Fletcher and Pride. ${ }^{16}{ }^{17}$ The diagnosis was based on the signs and symptoms, pulmonary function tests (including forced expiratory volume in one second $\left(\% \mathrm{FEV}_{1}\right)$, residual volume (RV)/total lung capacity (TLC), carbon monoxide transfer factor (TLCO)) under stable conditions (not at the time of exacerbation of the disease), and chest radiography (including CT scan). There were no patients with asthma included in the COPD group; $75 \%$ of the patients were receiving methylxanthine and $66 \%$ inhaled anticholinergic agents; $25 \%$ received inhaled $\beta$ adrenergic agonist and inhaled corticosteroid,

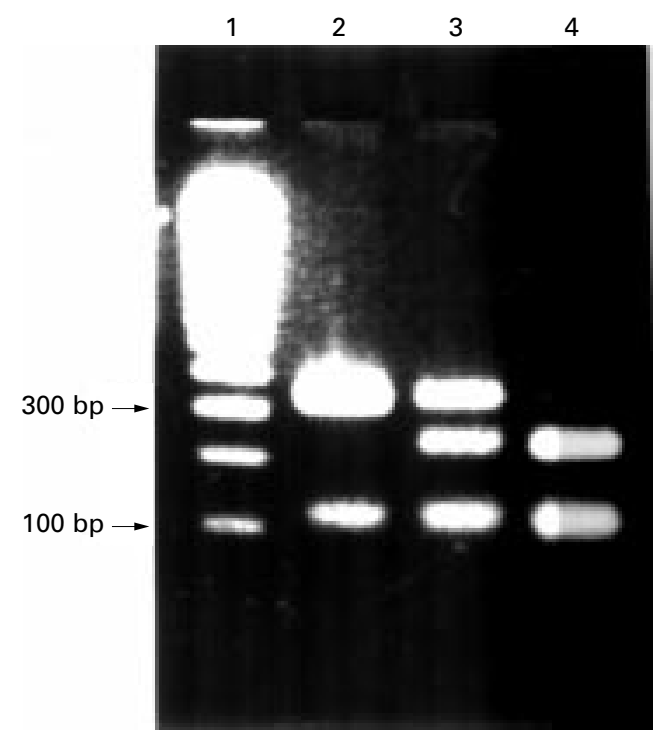

Figure 2 Representative electrophoresis gels with band visualisation in exon 5 polymorphism of GSTP1 showing only larger diagnostic bands. Lane 1, 100-1000 bp DNA ladder (the difference of each band is $100 \mathrm{bp}$ ); lane 2, homozygous mutant; lane 3, heterozygote; lane 4, homozygous wild type. of which $15 \%$ received an oral $\beta$ adrenergic agonist and less than $10 \%$ received oral prednisone. To remove the effects of sex differences and to match the smoking history, all control subjects were male and were current smokers free from pulmonary disease with normal pulmonary function test results. None of the control subjects had family members affected by COPD.

Genomic DNA was extracted from whole blood using the QIAamp Blood Kit (QIAGEN Inc, California, USA).

Because GSTP1 has been known to have two genetic polymorphisms in exon 5 and exon 6, two separate PCR assays were used to detect the two polymorphisms as follows: guanine to adenine transition in exon 5 changes Ile 105 to Val, and transition of cytosine to thymidine in exon 6 changes Ala114 to Val at the protein level. The PCR and restriction fragment length polymorphism (RFLP) studies were performed using methods described by Watson et al ${ }^{18}$ with a slight modification.

Briefly, the assay for the exon 5 variant uses the primer pair EX5-1 (5'-GTAGTTTGCC CAAGGTCAAG-3' starting at $2306 \mathrm{bp}$ in GSTP1 complete code, GDB accession number X08058) and EX5-2 (5'-AGCCACCTGAGG GGTAAG-3' starting at $2721 \mathrm{bp}$ ). PCRs were carried out using the program temperature control system PC-800 (Astec, Tokyo, Japan). 100 ng of genomic DNA was added to a mixture containing $11 \mathrm{pmol}$ of each primer, $0.5 \mathrm{U}$ AmpliTaq Gold with $1.5 \mu 110 \times$ PCR buffer (containing $25 \mathrm{mM} \mathrm{MgCl}_{2}$ ) and $1.5 \mu \mathrm{l}$ of $10 \times$ dNTPmix (Perkin-Elmer Applied Biosystems Division, California, USA) in a final volume of $15 \mu \mathrm{l}$. The "auto-hot start" was used to prevent non-specific priming in the first cycle of PCR. Following an initial denaturation step at $95^{\circ} \mathrm{C}$ for 12 minutes, 15 cycles of PCR were performed (denaturation at $95^{\circ} \mathrm{C}$ for $30 \mathrm{sec}-$ onds, annealing at $58^{\circ} \mathrm{C}$ for 30 seconds, elongation at $72^{\circ} \mathrm{C}$ for 60 seconds), followed by 25 cycles of amplification (denaturation at $95^{\circ} \mathrm{C}$ for 30 seconds, annealing at $55^{\circ} \mathrm{C}$ for 30 seconds, elongation at $72^{\circ} \mathrm{C}$ for 60 seconds) and one cycle of elongation at $72^{\circ} \mathrm{C}$ for five minutes. The PCR products were digested for two hours at $37^{\circ} \mathrm{C}$ with five units of Alw26I (Fermentas Inc, Vilnius, Lithuania).

The assay for the exon 6 variant was performed with the primer pair EX6-1 (5'-GGGAGCAAGCAGAGGAGAAT-3' at $3402 \mathrm{bp}$ ) and EX6-2 (5'-CAGGTTGTAGT CAGCGAAGGAG-3'). Following an initial denaturation step at $95^{\circ} \mathrm{C}$ for 12 minutes, 40 cycles of PCR were carried out (denaturation at $95^{\circ} \mathrm{C}$ for 30 seconds, annealing at $62^{\circ} \mathrm{C}$ for 30 seconds, and elongation at $72^{\circ} \mathrm{C}$ for $60 \mathrm{sec}-$ onds) followed by one cycle of elongation at $72^{\circ} \mathrm{C}$ for five minutes. The PCR products were digested for two hours at $37^{\circ} \mathrm{C}$ with 5 units of AciI (New England BioLabs Inc, Massachusetts, USA). All the digests were electrophoresed on a gel with 3.5\% Ultrapure Agarose (GibcoBRL, Maryland, USA) containing ethidium bromide. These assays are illustrated in fig 1 and the actual bands electrophoresed are shown in fig 2 . 
Table 1 Basic characteristics of the COPD and control groups

\begin{tabular}{lll}
\hline & COPD $(n=53)$ & Control $(n=50)$ \\
\hline Age (years) & $68.7(9.4)$ & $56.7(4.1)$ \\
Pack years & $50.4(4.2)$ & $42.9(1.9)$ \\
\%VC & $90.3(2.8)$ & $102.0(1.5)$ \\
FEV $_{1} / \mathrm{FVC}(\%)$ & $44.7(1.6)$ & $80.2(0.6)$ \\
$\% \mathrm{FEV}_{1}$ & $46.7(2.3)$ & $96.4(1.5)$ \\
\hline
\end{tabular}

All values are mean (SE).

$\mathrm{VC}=$ vital capacity; $\mathrm{FEV}_{1}$ = forced expiratory volume in one second; FVC = forced vital capacity.

ANALYSIS OF DATA

The difference in allele distribution and frequency in each group was examined by the $\chi^{2}$ test, with the Fisher exact test where appropriate. Age, smoking index expressed as pack years (number of packs of tobacco smoked per day $\times$ number of years smoked) and values of pulmonary function tests in the two groups were compared using the unpaired Student's $t$ test. These analyses were performed using the StatView J-4.5 application program (SAS Institute Inc, North Carolina, USA). p values of $<0.05$ were considered statistically significant. All values are represented as mean (SE).

\section{Results}

Age, smoking history, and the results of pulmonary function tests of the two groups are shown in table 1 . The difference in the mean tobacco consumption between the COPD patients and the control subjects was not significant. The mean (SE) $\mathrm{FEV}_{1} / \mathrm{FVC}$ of the COPD group was approximately 50\% lower than the control group (44.7 (1.6)\% vs 80.2 $(0.6) \%)$.

The results of genetic polymorphism in exons 5 and 6 of GSTP1 are summarised in table 2. In exon 5 105Ile homozygote was the predominant genotype in each group; 105Val homozygosity is very uncommon in the Japanese population and in the present study only two individuals with this homozygote were found in the control group. 105Ile genotype was significantly more frequent in the COPD group than in control group (0.90 and 0.74, respectively). The odds ratio for GSTP1/Ile105 homozygotes versus all other genotypes was 3.5 (95\% CI 2.7 to 4.6 ) for COPD. However, in exon 6 the 114Ala allele was found in both the COPD and control groups, and the $114 \mathrm{Val}$ allele was not found in either group.

\section{Discussion}

Chronic tobacco smoking is the major risk factor for the development of COPD, but only a relatively small proportion of smokers actually develop airway obstruction. Genetic factors are related to this susceptibility and include genes regulating the protease-antiprotease and oxidant-antioxidant interactions. It has recently been suggested that genetic polymorphisms of cytochrome $\mathrm{P} 450,{ }^{19}$ microsomal epoxide hydrolase (mEPHX), ${ }^{20}$ and tumour necrosis factor- $\alpha^{21}$ may be associated with emphysema or COPD. In this report the contribution of gene encoding xenobiotic enzymes which metabolise the tobacco constituents has been investigated.

We have studied the genotype distribution of polymorphisms at positions 105 and 114 in GSTP1, an enzyme involved in protection against xenobiotics in the lung. The 105Ile genotype was found more frequently in the COPD group than in the control group, and the odds ratio for homozygotes of 105Ile was 3.5. The allele frequency of 105 amino acid of the control group is reported to be more similar to Taiwanese subjects than to Caucasians. ${ }^{18}$ The activity of this enzyme is influenced by substitutions in position 105 which is located in the hydrophobic substrate binding site. The effect of this polymorphism varies with the type of chemical reaction - for example, in reactions of Michael addition, nucleophilic addition and epoxide conjugation, and catalytic activity of GSTP $1 .{ }^{12}$ Although individuals with the 105 Val allele have a higher risk of developing lung cancer than those with the 105Ile allele, ${ }^{13}$ it was also recently suggested that GSTP1/ Val105 has a higher catalytic efficiency than GSTP1/Ile105 for carcinogenic aromatic epoxides. ${ }^{14}$ These findings therefore suggest that GSTP1 might catalyse the detoxification of some xenobiotics in the tobacco smoke and that this reaction might be also catalysed by GSTM, mEPHX, and cytochrome P4501A1, but not by glutathione peroxidase. In addition, GSTP1 differs from other GSTs in not having glutathione peroxidase activity. ${ }^{22}$ Epoxides can be detoxified principally by GSTs or epoxide hydrolases, and these have been reported to be associated with emphysema. ${ }^{20}$

Furthermore, gene expression of GSTP1 in alveoli, alveolar macrophages, and respiratory bronchioles is more abundant than of GSTM and other GSTs which are not expressed in the lung. ${ }^{15}$ It is therefore possible that GSTP1 may play an important role in local detoxification of xenobiotics such as mEPHX in the lung.

Although exposure to tobacco smoke can alter the expression of some xenobiotic metabolising enzymes, Watson et al found no apparent relationship between smoking history

Table 2 Distribution of exon 5 and exon 6 polymorphism of GSTP1 genotypes in COPD and control groups

\begin{tabular}{|c|c|c|c|c|c|}
\hline & \multicolumn{3}{|c|}{ Number of individuals (\% of group) } & \multirow{2}{*}{$\begin{array}{l}\text { Odds ratio (95\% CI) } \\
\text { for homozygotes of } \\
\text { wild type }\end{array}$} & \multirow[b]{2}{*}{$\begin{array}{l}\text { Major allele } \\
\text { frequency }\end{array}$} \\
\hline & Homozygous wild type & Heterozygote & $\begin{array}{l}\text { Homozygous } \\
\text { mutant }\end{array}$ & & \\
\hline \multicolumn{6}{|c|}{ Exon 5 polymorphism (Ile105Val) } \\
\hline Control group & $26(52 \%)$ & $22(44 \%)$ & $2(4 \%)$ & 1 & 0.74 \\
\hline COPD group & $42(79 \%)^{\star}$ & $11(21 \%)$ & $0(0 \%)$ & $3.5(2.7$ to 4.6$)$ & 0.90 \\
\hline \multicolumn{6}{|c|}{ Exon 6 polymorphism (Ala114Val) } \\
\hline Control group & $50(100 \%)$ & $0(0 \%)$ & $0(0 \%)$ & & 1.00 \\
\hline COPD group & $53(100 \%)$ & $0(0 \%)$ & $0(0 \%)$ & & 1.00 \\
\hline
\end{tabular}

${ }^{\star} \mathrm{p}=0.009$. 
and 1-chloro-2,4-dinitrobenzene (CDNB) activity, which reflects the activity of the GSTs, in lung tissue. They also reported that individuals with the 105Val allele tended to have lower CDNB activity in the lung tissue of nonsmokers, former smokers, and current smokers than those with the 105Ile allele, although the difference was not statistically significant. ${ }^{18}$

Tobacco smoke contains about 4000 substrates including carcinogenic agents and other possible causative agents of COPD such as volatile aldehydes and hydrogen cyanide. ${ }^{23}$ GSTP1 prevents the inhibition of embryonic retinoic acid synthesis by aldehydes of lipid peroxidation. ${ }^{24}$ It was also found recently that normal alveoli were restored by treatment with retinoic acid in elastase induced experimental emphysema. ${ }^{25}$ In contrast, it has also been reported that retinoic acid treatment increased GSTP1 gene expression significantly in MGR3 cells, a human glioblastoma multiform cell line. ${ }^{26}$ It is therefore also possible that the preventive role of GSTP1 in the development of COPD may be explained by its interaction with retinoic acid.

In this study the 114 Val allele was not found in either group of subjects. If this allele exists in the Japanese population it is very rare and is therefore not an important contributing factor in the development of COPD in the Japanese population.

In summary, we have shown that the 105Ile genotype in exon 5 of GSTP1 might be associated with the pathogenesis of COPD. In terms of the number of subjects examined, this study is a preliminary work and a further study using a larger population is needed to clarify the association of the exon 5 polymorphism of the GSTP1 gene with individual susceptibility to development of COPD. Furthermore, in addition to the possible link between mEPHX and emphysema, investigation of the function of other xenobiotic enzymes such as GSTP1 may provide more insight to the pathogenesis of emphysema or COPD in smokers. This study was partly supported by a grant from the Smoking
Research Foundation, and Grant-in-Aid for Scientific Research (c) from the Ministry of Education, Science, Sports and Culture, Japan.

1 Siafakas NM, Vermeire P, Pride NB, et al on behalf of the Task Force. Optimal assessment and management of chronic obstructive pulmonary disease (COPD). The European Respiratory Society Task Force. Eur Respir $\mathcal{7}$ European Respirator

2 Murray CJL, Lopez AD. Evidence-based health policy lessons from the Global Burden of Disease study. Science 1996;274:740-3.

3 Robin ED. Summary: symposium on pulmonary emphysema and proteolysis. In: Mittman C, ed. Pulmonary emphysema and proteolysis. New York: Academic Press, 1972: 527-37.

4 Church DF, Pryor WA. Free radical chemistry of cigarette smoke and its toxicological implications. Environ Health Perspect 1985;64:111-26.

5 Carp H, Miller F, Hoidal JR, et al. Potential mechanism of emphysema: alpha 1-proteinase inhibitor recovered from lungs of cigarette smokers contains oxidized methionine and has decreased elastase inhibitory capacity. Proc Natl Acad Sci USA 1982;79:2041-5.

6 Fletcher C, Peto R. The natural history of chronic airflow obstruction. BMF 1977;1:1645-8.

7 Bascom R. Differential susceptibility to tobacco smoke: possible mechanisms. Pharmacogenetics 1991;1:102-6.

8 Silverman EK, Chapman HA, Drazen JM, et al. Genetic epidemiology of severe, early-onset chronic obstructive pulmonary disease. Risk to relatives for airflow obstruction and chronic bronchitis. Am $\mathcal{F}$ Respir Crit Care Med 1998;157:1770-8.

9 Mannervik B. The isozymes of glutathione S-transferase. Adv Enzymol 1985;57:357-417.

10 Harrison DJ, Cantly AM, Rae F, et al. Frequency of glutathione S-transferase M1 deletion in smokers with emphysema and lung cancer. Hum Exp Toxicol 1997;17:356-60.

11 Board PG, Webb GC, Coggan M. Isolation of a cDNA clone and localization of the human glutathione -transferase 3 genes to chromosome ban

12 Johansson AS, Stenberg G, Widersten M, et al. Structureactivity relationships and thermal stability of human glutathione transferase $\mathrm{P} 1-1$ governed by the $\mathrm{H}$-site residue 105. F Mol Biol 1998;278:687-98.

13 Ryberg D, Skaug V, Hewer A, et al. Genotypes of glutathione transferase $\mathrm{M} 1$ and $\mathrm{P} 1$ and their significance for lung DNA adduct levels and cancer risk. Carcinogenesis 1997;18:1285-

14 Sundberg K, Johansson AS, Stenberg G, et al. Differences in the catalytic efficiencies of allelic variants of glutathione transferase P1-1 towards carcinogenic diol epoxides of transferase P1-1 towards carcinogenic diol epoxides of
polycyclic aromatic hydrocarbons.Carcinogenesis 1998;19: polycyc
$433-6$.

15 Cantlay AM, Smith CA, Wallace WA, et al. Heterogeneous expression and polymorphic genotype of glutathione S-transferases in human lung. Thorax 1994;49:1010-4.

16 Siafakas NM, Vermeire P, Pride NB, et al. Optimal assessment and management of chronic obstructive pulmonary disease (COPD). Eur Respir f 1995; 8:1398420 .

17 Fletcher CM, Pride NB. Definition of emphysema, chronic bronchitis, asthma, and airflow obstruction: 25 years on from the Ciba symposium. Thorax 1984; 39:81-5.

18 Watson MA, Stewart RK, Smith GBJ, et al. Human glutathione S-transferase P1 polymorphisms: relationship to lung tissue enzyme activity and population frequency distribution. Carcinogenesis 1998; 19:275-80.

19 Cantlay AM, Lamb D, Gillooly $\mathrm{M}$, et al. Association between the CYP1A1 gene polymorphism and susceptibility to emphysema and lung cancer. $\mathcal{F}$ Clin Mol Pathol 1995; 48:M210-4.

20 Smith CAD, Harrison DJ. Association between polymorphism in gene for microsomal epoxide hydrolase and susceptibility to emphysema. Lancet 1997;350:630-3.

21 Huang S-L, Su C-H, Chang S-C. Tumor necrosis factor-alpha gene polymorphism in chronic bronchitis. Am 7 Respir Crit Care Med 1997;156:1436-9.

22 Hurst R, Bao Y, Jemth P, et al. Phospholipid hydroperoxide glutathione peroxidase activity of human glutathione transferases. Biochem $\mathcal{F}$ 1998;332:97-100.

23 Hoffmann D, Hoffmann I. The changing cigarette, 19501995. F Toxicol Environ Health 1997;50:307-64.

24 Chen H, Juchau MR. Inhibition of embryonic retinoic acid synthesis by aldehydes of lipid peroxidation and prevention of inhibition by reduced glutathione and glutathione S-transferases. Free Radic Biol Med 1998;24:408-17.

25 Massaro GD, Massaro D. Retinoic acid treatment abrogates elastase-induced pulmonary emphysema. Nature Med 1997;3:675-7.

26 Lo HW, Ali-Osman F. Genomic cloning of hGSTP1C and allelic human pi class glutathione S-transferase gene variant and functional characterization of its retinoic acid response elements. F Biol Chem 1997;272:32743-9. 